\title{
Post-extraction Assessment of the Child's Dental Attitude Changes after Providing an Ice Cream
}

\author{
Karthik Nair ${ }^{1}$, Chikkanarasaiah Nagarathna ${ }^{2}$
}

\begin{abstract}
Introduction: The use of ice or cold application post-extraction manages pain, anxiety, and behavioral problems in children. The patient management skill brings out a positive attitude toward dental treatment.

Aim: The aim of the study is to identify the posttreatment alteration in the child's apprehensiveness toward dental extractions under local anesthesia (LA).

Materials and methods: A study consisting of two groups $(n=20)$, aged 6-8 years old children were included. Extraction was done under LA. Data were collected through a questionnaire which was given immediately after the procedure and 30 minutes later after giving an ice cream. Result: In the present study, the results were statistically significant as $80-90 \%$ of the children in the study group who received ice cream felt less pain, discomfort, and apprehension than $50 \%$ of the children who did not receive an ice cream.

Conclusion: Reinforcement techniques have always provided a positive influence on the child's response to any dental procedures.

Keywords: Dental attitude, Extraction, Pain.

Journal of Health Sciences \& Research (2019): 10.5005/jp-journals-10042-1076
\end{abstract}

\section{INTRODUCTION}

Children's apprehensiveness toward the dental procedures can be reasoned due to dental anxiety and fear which denotes the dental phobia that is the fear or anxiety developed due to the challenge/ threat of dental examination influenced by day-to-day happening causing the prolonged delay in the treatment. ${ }^{1}$ Dental extraction, itself can stimulate an anxiety and fear for both the dentist and the patient. Patient's dental fear may be due to any unpleasant experience or due to any threatening or a false information, thus, for any treatment, the fear of pain can be the prime cause of failure for rendering an effective treatment or good care. ${ }^{2,3}$

A key to a propitious treatment for a disruptive child always lies in the behavior management technique opted for completing a procedure. So selecting a technique should be based on child's age, anxiety, parental attitude, nature of the procedure to be rendered, and legal repercussion. ${ }^{4}$ According to Fields et al., the behavior management techniques like voice control, mouth props, positive reinforcement, and tell-show-do are nearly acceptable for all the dental procedure, ${ }^{4}$ and, according to Murphy et al., the least aggressive behavior management techniques are more acceptable by the parent when compared to the technique like employing drugs and physical restrains. ${ }^{5}$

One of the important concepts of learning theory is the reinforcement, positive reinforcement is always recommended to obtain a desired behavior. Immediate reinforcement or reward in the form of a gift is always effective in behavior modification than a delayed reward according to the clinical research psychology. As it is always told, any tangible prizes are more successful than intangible verbal appreciations. ${ }^{6}$

Cold application is found to be a simple and inexpensive method for a nonpharmacologic intervention and has been accepted for pain management. Studies related to pain caused due to injection revealed a significant positive finding in adults but not
${ }^{1}$ Department of Pediatric and Preventive Dentistry, RajaRajeswari Dental College and Hospital, Bengaluru, Karnataka, India

${ }^{2}$ Department of Pedodontics and Preventive Dentistry, RajaRajeswari Dental College and Hospital, Bengaluru, Karnataka, India

Corresponding Author: Karthik Nair, Department of Pediatric and Preventive Dentistry, RajaRajeswari Dental College and Hospital, Bengaluru, Karnataka, India, Phone: +91 9035282442, e-mail: karthik1210@yahoo.com

How to cite this article: Nair K, Nagarathna C. Post-extraction Assessment of the Child's Dental Attitude Changes after Providing an Ice Cream. J Health Sci Res 2019;10(1):11-14.

Source of support: Nil

Conflict of interest: None

in children. ${ }^{7}$ An ice cream or a popsicle may have both physiological effect on the anesthetized soft tissue and it could be used as positive reinforcer (reward) to elevate their acceptance toward the invasive procedures like extraction.

In the year 1958 , Clark, Hellon, and Lind found that at $27^{\circ} \mathrm{C}$, conduction is suppressed as well as the rate of impulses is decreased along the neurons. At the temperature below $20^{\circ} \mathrm{C}$ decreases the production of acetylcholine, this delays the transmission of impulses through the cooled neurons causing an asynchronous conduction. ${ }^{8}$

Studies have shown the importance of using an ice popsicle to restrict the self-mutilation, but little research is offered in support of using an ice popsicle or a gift as a reinforcement technique after dental extraction. A gift brings about a positive attitude, but it does not have any physiological effect on the extracted site. Dental literature lacks the benefits of providing an ice popsicle after dental extraction.

So this study was conducted to identify the posttreatment alteration in child's apprehensiveness toward dental extraction under LA after providing ice popsicles.

() The Author(s). 2019 Open Access This article is distributed under the terms of the Creative Commons Attribution 4.0 International License (https://creativecommons. org/licenses/by-nc/4.0/), which permits unrestricted use, distribution, and non-commercial reproduction in any medium, provided you give appropriate credit to the original author(s) and the source, provide a link to the Creative Commons license, and indicate if changes were made. The Creative Commons Public Domain Dedication waiver (http://creativecommons.org/publicdomain/zero/1.0/) applies to the data made available in this article, unless otherwise stated. 


\section{Materials and Methods}

The study was conducted on 40 children selected randomly from among the patients came to the Department of Pedodontics. The total group was divided into two groups $(n=20)$ as the control (do not receive ice cream) and the test group (received an ice cream). Informed written consent was received from all subjects before collecting the sample. A routine general physical and oral examination were carried out and recorded. For the present study, healthy children between the age group of 6 and 8 years entailed for the treatment of grossly decayed teeth and tooth with mobility were included and the children with special healthcare needs were omitted from the study.

\section{Questionnaire}

A questionnaire form (Fig. 1) consists of a set of six questions which was made for parents or caretakers as well as for the evaluators or clinicians. The first three questions highlight the child's apprehensiveness on parent's perspective. The Wong-Baker FACES pain rating scale (FPS) was used for assessing the child's discomfort due to pain at the particular time. The child was elucidated about the FPSs and the faces and was asked to mark the apt face based on the treatment experience. The final two questions were meant for the clinician, the child's behavior is been the rated using the visual analog scale (VAS) and the responder details were also been mentioned. For the present study, the FPS shows good construct validity as a self-report pain measure and was comparatively easy for young patients to express the pain they experienced.

\section{Procedure}

All the extraction was carried out under LA using 2\% lignocaine. Immediately after the procedure, a postoperative questionnaire was given to the experimental group or test group and the control group (did not receive an ice cream), both the parent and the child were asked to fill the questionnaire. After the initial recordings were made (around 15 minutes after the procedure), an ice cream was provided to the child and the child was instructed to consume it immediately.

After 30 minutes post-extraction, the same questionnaire was repeated and asked to fill their views at that point of time.

All the questionnaires were analyzed and assessed by a single operator and were evaluated.

\section{Statistical Analysis}

The analysis was done using the SPSS IBM SPSS (Statistical Package for Social Sciences) software for Windows, Version 22.0, released in 2013, Armonk, NY: IBM Corp. and it will be used for statistical analysis.

\section{Descriptive Statistics}

- Descriptive analysis of all the study variables was done using mean and standard deviation for quantitative variables, frequency, and proportions for categorical variables.

\section{Inferential Statistics}

- The Chi-square test was used to assess the difference in the parent's attitude toward their child dental treatment between the two groups at each time interval.
- The independent Student $t$ test was used to compare the differences in the mean Wong-Baker FPS and VAS scores between two groups at different time intervals.

The paired Student $t$ test was used to compare the differences in the mean Wong-Baker FPS and VAS scores between the two time intervals ( 0 minutes and after 30 minutes) within each group.

\section{Results}

Table 1 describes that a significant higher proportion of parents (90\%) in the experimental group felt that their children either had pain and discomfort ( $p=0.006$ ) or they were crying or yelling ( $p=0.03$ ) compared to the $50-60 \%$ of the parents in the control group after 30 minutes of intervention.

The mean Wong Baker scale (WBC) score in the control group was higher i.e. $1.75 \pm 0.85$ as compared to the experimental group $(1.5 \pm 1.05)$; however, results were not statistically significant. But at the end of 30 minutes, the mean WBC score in the control group $(2.70 \pm 1.63)$ was higher when compared to the experimental group $(1.20 \pm 1.36)$ and the result turned out to be statistically significant as mentioned in Table 2.

So as per the present study, children had a positive attitude toward the dental procedures. There was a significant difference in the child's behavior and approach toward the invasive procedures like dental extractions.

\section{Discussion}

Providing an ice cream after the dental procedure has dual effects of both positive reinforcement and for subsiding the pain. Generally, there will be a discomfort after the dental extractions due to the pain and anesthesia. ${ }^{9}$

Behavior management always brings a drastic difference in the way of child's nature and attitude toward any type of dental procedure, and, as claimed by Wright et al., the acceptance of providing a reward in the dental office is always agreed. ${ }^{10}$

In our present study, the results showed a significant difference in the child's attitude after providing an ice cream, which was identified using the Wong-Baker FPS when compared to the children who did not receive an ice cream, where it can concluded that the ice cream might have a considerable effect on the soft tissue as it was provided after the procedure.

When compared between two time groups and according to the response, i.e. after 0 and 30 minutes, there was a relatively much difference in pain, discomfort after 30 minutes posttreatment when compared with the response given after 0 minutes, and, as per the questionnaire, the parents also reported that their children were neither crying nor yelling after providing an ice cream and there was a considerable difference in the apprehensiveness toward tooth extractions. This basically works on a fact that neural signals evoked by the cold are transmitted exclusively by the A-fibers and not by unmyelinated C-fibers. Therefore, it is clear that A-fibers are sufficient to activate descending analgesia producing system. A-fibers that carry cold activates inhibitory fibers in the dorsolateral funiculus (these mediated the analgesia produced by morphine and electrical stimulation of the periaqueductal gray matter). ${ }^{11}$

Our study faced some limitations, as the study was done within a short span, the results may have biased. The study was done with a limited number of samples and with limited questions so if the sample and the questions were increased, the results would have varied. 
Name:

OP No:

Phone Number:

Tooth Treated:

Mark the appropriate answer

1. Does the child complain about the pain and discomfort?

\begin{tabular}{|c|c|}
\hline Time (0 min) & Time (30 min) \\
\hline Yes & Yes \\
\hline No & No \\
\hline
\end{tabular}

2. Is the child crying or yelling?

\begin{tabular}{|c|c|}
\hline Time $(0 \mathrm{~min})$ & Time (30 min) \\
\hline Yes & Yes \\
\hline No & No \\
\hline
\end{tabular}

3. Is the child apprehensive about the treatment

\begin{tabular}{|c|c|}
\hline Time (0 min) & Time (30 min) \\
\hline Yes & Yes \\
\hline No & No \\
\hline
\end{tabular}

4. The child's feeling:

0-no pain $\quad$ 1-very little pain $\quad$ 2-slightly painful $\quad 3$ - painful 4-very painful 5- unbearably painful

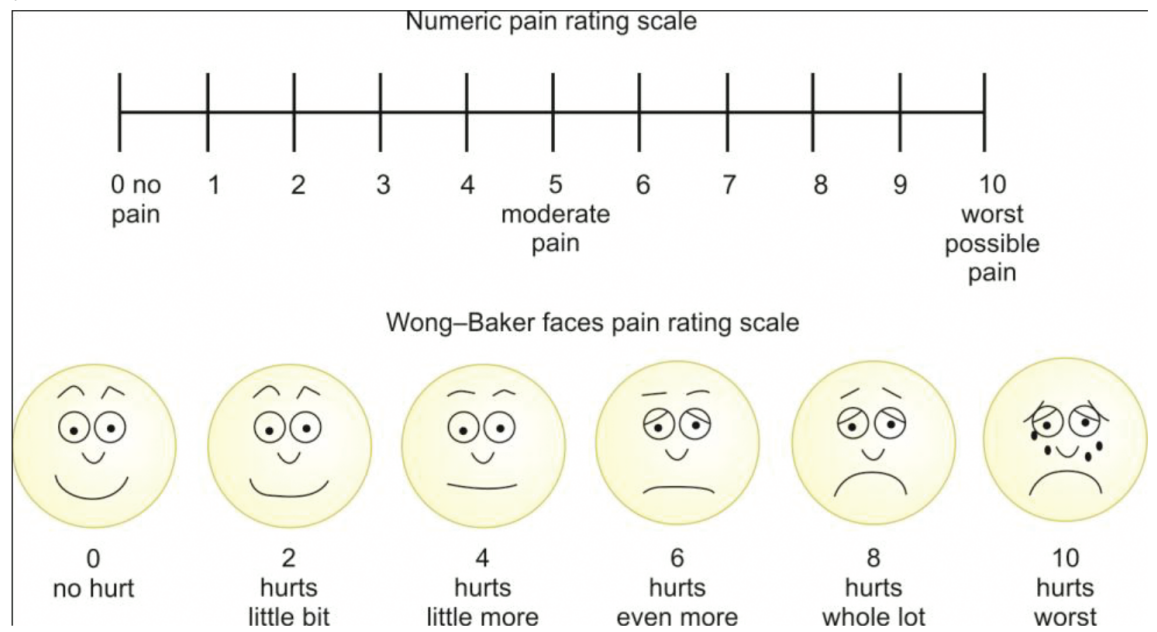

5. The child's behavior, rated from 0 to 10 using a visual analog scale

\begin{tabular}{|c|c|}
\hline 0 & \\
\hline+30 & \\
\hline
\end{tabular}

0

6. The questionnaire was filled by

\begin{tabular}{|c|c|}
\hline Time (0 $\mathrm{min})$ & Time (30 min) \\
\hline Mother & Mother \\
\hline Father & Father \\
\hline Other & Other \\
\hline
\end{tabular}

Fig. 1: Questionnaires for the parents regarding the attitude toward the dental treatment 
Table 1: Comparison of the parents'attitude toward their children's dental treatment at different time intervals between two groups

\begin{tabular}{|c|c|c|c|c|c|c|c|c|}
\hline \multirow[b]{2}{*}{ Questions } & \multirow[b]{2}{*}{ Time } & \multirow[b]{2}{*}{ Categories } & \multicolumn{2}{|c|}{ Control group } & \multicolumn{2}{|c|}{ Experimental group } & \multirow[b]{2}{*}{$c^{2}$ value } & \multirow[b]{2}{*}{$p$ value } \\
\hline & & & $n$ & $\%$ & $N$ & $\%$ & & \\
\hline \multirow[t]{4}{*}{ Q1 } & 0 minutes & Yes & 20 & 100 & 14 & 70 & 7.059 & 0.008 \\
\hline & & No & 0 & 0 & 6 & 30 & & \\
\hline & 30 minutes & Yes & 10 & 50 & 2 & 10 & 7.619 & 0.006 \\
\hline & & No & 10 & 50 & 18 & 90 & & \\
\hline \multirow[t]{4}{*}{ Q2 } & 0 minutes & Yes & 20 & 100 & 12 & 60 & 10.000 & 0.002 \\
\hline & & No & 0 & 0 & 8 & 40 & & \\
\hline & 30 minutes & Yes & 8 & 40 & 2 & 10 & 4.800 & 0.03 \\
\hline & & No & 12 & 60 & 18 & 90 & & \\
\hline \multirow[t]{4}{*}{ Q3 } & 0 minutes & Yes & 19 & 95 & 17 & 85 & 1.111 & 0.29 \\
\hline & & No & 1 & 5 & 3 & 15 & & \\
\hline & 30 minutes & Yes & 10 & 50 & 4 & 20 & 3.956 & 0.04 \\
\hline & & No & 10 & 50 & 16 & 80 & & \\
\hline
\end{tabular}

Table 2: Comparison of mean Wong-Baker FPS and VAS scores at different time intervals between two groups

\begin{tabular}{|c|c|c|c|c|c|c|c|c|}
\hline Variables & Group & $N$ & Mean & $S D$ & SEM & Mean diff & $t$ & $p$ value \\
\hline \multirow[t]{2}{*}{ WB scale } & Control group & 20 & 1.75 & 0.85 & 0.19 & 0.25 & 0.827 & 0.41 \\
\hline & Experimental group & 20 & 1.50 & 1.05 & 0.24 & & & \\
\hline \multirow[t]{2}{*}{ VAS_0 minutes } & Control group & 20 & 3.10 & 1.37 & 0.31 & 0.10 & 0.184 & 0.86 \\
\hline & Experimental group & 20 & 3.00 & 2.00 & 0.45 & & & \\
\hline \multirow[t]{2}{*}{ VAS_30 minutes } & Control group & 20 & 2.70 & 1.63 & 0.36 & 1.50 & 3.164 & 0.003 \\
\hline & Experimental group & 20 & 1.20 & 1.36 & 0.30 & & & \\
\hline
\end{tabular}

\section{CONCLUSION}

- The study concluded that there was a significant change in the attitude of the children toward dental extractions.

- Proper behavior management always plays an important not only for the children but also for the parents and their attitude toward dental procedures.

- Children who received the ice cream after extraction under LA reported that they felt better suffered less from pain.

\section{References}

1. American Psychiatric Association. Diagnostic and Statistical Manual of Mental Disorders. 4th ed., Washington DC: American Psychiatric Press; 1994.

2. Ost LG. Age of onset in different phobias. J Abnorm Psychol 1987;96(3):223-229. DOI: 10.1037/0021-843X.96.3.223.

3. Milgrom $P$, Mancl $L$, et al. Origins of childhood dental fear. Behav Res Ther 1995;33(3):313-319. DOI: 10.1016/0005-7967(94) 00042-I.
4. Fields HW, Machen JB, et al. Acceptability of various behavior management techniques relative to types of dental treatment. Pediatr Dent 1984 Dec 1;6(4):199-203.

5. Machen JB. Parental acceptance of pediatric dentistry behavior management techniques. Pediatr Dent 1984 Dec;6(4):193.

6. Sauls J. Efficacy of cold for pain: fact or fallacy? Online J Knowl Synth Nurs 1999 Oct 22;6:8.

7. Behaviour Management In Dentistry For Children Second Edition by Gerald Z. Wright Ari Kupietzky.

8. Clark R, Hellon $R$, et al. The duration of sustained contractions of the human forearm at different muscle temperatures. J Physiol 1958;143:454-473. DOI: 10.1113/jphysiol.1958.sp006071.

9. Ram D, Peretz B. Assessment of the pain reaction of children receiving periodontal ligament local anesthesia using a computerized device (Wand).

10. Wright GZ, Lenchner V. Practical considerations for behavior management in Behavior Management in Dentistry for Children WB Saunders Co., Philadelphia, London, Toronto, 1975. J Clin Pediatr Dent 2003;27(3):247-249.

11. Melzack R, Guite $S$, et al. Relief of dental pain by ice massage of the hand. Can Med Assoc J 1980 Jan 26;122(2):189. 